\title{
EXPENDITURE SURVEY ON CONTINUED VENO-VENOUS HEMODIALYSIS PROCEDURE IN THE INTENSIVE CARE UNIT ${ }^{1}$
}

\author{
Lígia Maria dal Secco ${ }^{2}$ \\ Valéria Castilho ${ }^{3}$
}

Secco LMD, Castilho V. Expenditure survey on continued veno-venous hemodialysis procedure in the intensive care unit. Rev Latino-am Enfermagem 2007 novembro-dezembro; 15(6):1138-43.

This study aimed to characterize patients submitted to dialytic treatment with CVVHD in ICUs; monitor procedure time duration; estimate nurses' labor wages and; estimate the direct procedures mean costs. The study was developed in a public teaching hospital located in São Paulo, Brazil. A total of 93 procedures performed in 50 patients composed the sample. The results showed the predominance of male patients (62\%); mean age was 60.8 years old; ICU hospitalization time was 19.2 days; $86 \%$ of the patients died; $76 \%$ of the patients presented acute renal insufficiency and, mean procedure time per patient was 1.9. The mean procedure duration was 26.6 hours. The mean cost of nurses' wages were $R \$ 592.04$ which represented $28.7 \%$ of the total cost. The mean total expenditure was $R \$ 2,065.36$ ranging from $R \$ 733.65$ to $R \$ 6,994.18$.

DESCRIPTORS: intensive care units; renal dialysis; costs and cost analysis

\section{LEVANTAMIENTO DEL COSTO DEL PROCEDIMIENTO DE HEMODIÁLISIS VENA-VENOSA CONTINUA EN UNIDADES DE TERAPIA INTENSIVA}

El objetivo de este estudio fue identificar características sócio-demográficas de los pacientes sometidos al tratamiento de Hemodiálisis Vena-Venosa Continua (CVVHD) en Unidades de Terapia Intensiva (UTIs); identificar el tiempo de duración de los procedimientos; calcular el costo del tiempo de los enfermeros y evaluar el costo promedio directo de los procedimentos. El estudio fue realizado en un hospital escuela público en la ciudad de São Paulo. La muestra fue constituida por 93 procedimientos realizados en 50 pacientes. Los resultados mostraron la predominancia del sexo masculino (62\%); la edad promedia fue de 60,8 años; el tiempo promedio de permanencia en la UTI fue de 19,2 días; el 86\% evolucionó a óbito y el promedio del número de los procedimientos por paciente fue de 1,9 días. La insuficiencia renal aguda (IRA) está presente en el $76 \%$ de los pacientes. La duración promedia fue de 26,6 horas. El costo del tiempo del enfermero fue en promedio $R \$ 592,04$ y representó el 28,7\% del costo total. El costo total promedio del procedimiento fue de $R \$ 2.065,36$, con variación de $R \$ 733,65$ a $R \$ 6.994,18$.

DESCRIPTORES: unidades de terapia intensiva; diálisis renal; costos y análisis de costo

\section{LEVANTAMENTO DO CUSTO DO PROCEDIMENTO DE HEMODIÁLISE VENO-VENOSA CONTÍNUA EM UNIDADES DE TERAPIA INTENSIVA}

Os objetivos deste estudo foram: caracterizar a clientela submetida ao tratamento dialítico de Hemodiálise Veno-Venosa Contínua (CVVHD) em Unidades de Terapia Intensiva (UTIs), levantar o tempo de duração dos procedimentos, calcular o custo da mão-de-obra dos enfermeiros, estimar o custo médio direto dos procedimentos. O estudo foi desenvolvido em um hospital escola público no município de São Paulo. A amostra foi constituída por 93 procedimentos realizados em 50 pacientes. Os resultados mostraram predominância do sexo masculino (62\%), a idade média foi de 60,8 anos, o tempo médio de permanência na UTI foi de 19,2 dias, 86\% evoluíram a óbito e a média do número de procedimentos por paciente foi de 1,9. A insuficiência renal aguda (IRA) estava presente em $76 \%$ dos pacientes. A duração média do procedimento foi de 26,6 horas. O custo da mão-de-obra direta do enfermeiro foi em média $R \$ 592,04$, representando $28,7 \%$ do custo total. O custo total médio do procedimento foi de $R \$ 2.065,36$, variando de $R \$ 733,65$ a $R \$ 6.994,18$.

DESCRITORES: unidades de terapia intensiva; diálise renal; custos e análise de custo

${ }^{1}$ Extracted from Master Thesis; ${ }^{2}$ RN, MS in Nursing, Hospital das Clínicas, University of São Paulo at Ribeirão Preto, Medical School, Brazil; ${ }^{3}$ RN, PhD Professor, University of São Paulo at Ribeirão Preto, College of Nursing, Brazil 


\section{INTRODUCTION}

Intensive Care Units (ICU) have been appointed as one of the most costly places in hospital organizations. Due to continuous and rapid advancements in technology, new equipments have been installed in these sectors, requiring sophisticated accessories and material, in addition to specialized personnel to operate them.

Dialysis treatment has also developed greatly, due to scientific and technological advances, and it has happened more and more frequently at ICUs.

Since the advent of dialysis treatments and ICUs, a steady increase in the severity of baseline diseases has been observed, which present Acute Renal Failure (ARF) as an associated complication ${ }^{(1)}$.

ARF, which affects patients hospitalized at ICUs, presents a particular mortality and epidemiological profile ${ }^{(2)}$. The Brazilian Society of Nephrology (BSN) informs that these patients' mortality is close to $50 \%$ and that the condition of current patients with ARF is more severe than formerly ${ }^{(3)}$.

Despite efforts and investments in the area, the mortality of patients with ARF in ICUs remains high.

Renal substitution therapy is a complex procedure, demands precise equipment, specific material and duly trained professionals. It involves the multiprofessional ICU and Dialysis teams so that they can work together; because the first attends the patient directly and the later fully masters the specialty. Thus, the association between these parts is necessary in order to increase the actions' effect and save resources.

The limited availability of resources is a serious problem that affects not only public hospitals, which makes it necessary to identify the costs in care delivery. These data are essential for the management of hospital service costs, because this contributes in making decisions on the allocation of resources and future investments, in comparing and analyzing amounts paid by the SUS, which in turn can demonstrate the need for better funding allocation and also help in the negotiation of health plans and insurances.

Therefore, one of the great challenges in the health area is to find a balance between care quality and viable costs. The need to know the costs involved in care delivery is urgent in decision making on resource allocation ${ }^{(4)}$.
Studies found in literature, which proposed to measure the costs of dialysis procedures in ICUs, use different methodologies. It was also verified that there is no standardization in the service structure for this kind of treatment in the countries studied ${ }^{(5-11)}$. In Brazil, studies were found that only focused only on costs of dialysis procedures for chronic renal patients.

This study aimed to estimate the mean direct cost of the most frequent dialysis procedure in the ICUs of a large public teaching hospital in São Paulo, Brazil. This procedure is continuous venovenous hemodialysis (CVVHD), which corresponds to approximately $70 \%$ of the procedures performed in ICUs in the last two years.

This research aimed to characterize the clientele submitted to dialysis treatment with CVVHD in ICUs; estimate the length of the procedure; calculate the cost of nurses' work and estimate the direct mean cost of the procedures.

\section{CASES AND METHOD}

This is an exploratory, descriptive, retrospective, documental research with a qualitative approach, which analyzed the direct average cost of continuous venovenous hemodialysis (CVVHD) procedures in patients with renal failure and who were submitted to this kind of procedure during their ICU stay.

The direct costs of nurses' work (category that performs the procedure), material, medications and solutions consumed during the procedure were computed.

The costs of complementary exams and medical work were not considered because this kind of amount was not accessible. The depreciation cost of equipments was not inferred because they are acquired through a loan for use agreement system, charging only the devices and catheters used.

The fee of indirect costs was not added to the procedure's total cost because the ICUs' costs are calculated together with those of the nursing wards.

This study was developed at a large teaching hospital in São Paulo, Brazil, which that delivers quaternary care and offers approximately 2,200 beds, divided in Institutes, one of them with around 120 ICU beds, divided in ten distinct units.

The research project was evaluated and authorized by the Institution's Project Analysis Committee. 
The non-probabilistic intentional sample was composed of 93 procedures performed in 50 patients in the period from May 2005 to February 2006. This period was chosen because it is when the current hemodyalisis equipment started to be used at the ICUs.

For the data collection, an instrument composed of two parts was elaborated: one for the clients' demographic and clinical data; and the second part presented two worksheets: one for the registration of material and the other for the registration of medications and solutions consumed during the dialysis procedure in question, in addition to a space to take notes on occurrences.

Data were collection by the researcher from March 6 to May 31, 2006. The patients' files were analyzed by the researcher to complete the instrument.

Description of the procedure stages

Before data collection, the basic steps of the procedure were established with the Dialysis nurse: installation, maintenance and turnoff.

\section{Installation}

- Gather the necessary material;

- Position the dialysis machine close to the patient;

- Wash hands;

- Set up the specific Kit circuit of the equipment with the capillary dialyzer, faucet and simple equipment;

- Prime the system with physiological solution;

- Program the machine;

- Organize the extensions (threads), properly filled and occluded close to the catheter in order to connect them later;

- Wash hands;

- Put on mask;

- Put on non-sterile procedure gloves for removing the catheter dressing and discarding it, performing a visual inspection of the insertion site;

- Put on sterile gloves and clean the catheter with sterile gauze and antiseptic solution;

- Put on the sterile fenestrated field;

- Remove the occlusion covers from the catheter;

- Connect the syringe and declamp the route in order to aspire the heparine solution and test it by checking its permeability, one at a time;

- Connect the respective thread in each route, after disconnecting the syringe, respecting the flow the blood must follow;

- Turn on the equipment checking the system functioning with the program in course.

\section{Maintenance}

- Verify the patient's and machine vital parameters taking notes on a specific form of the Institution's dialysis procedures, every hour;

- Empty the dialysate and ultrafiltered volumes, performing partial and total balances of each bath on the specified form, every hour;

- The nurse must follow the time computed on the bath infusion pump equipment clock to control its length;

- Prepare, control and change dialysis solutions and others prescribed;

- Wash the system with physiological solution according to the medical prescription;

- When the alarm is set off, the nurse must attend to solve the problem, according to instructions in the equipment manual and, in case (s)he does not manage or is in doubt, (s)he must call the dialysis team.

Turnoff

- Gather the material to be used;

- Prepare syringes: of $10 \mathrm{ml}$ with physiological solution or distilled water, and the $3 \mathrm{ml}$ syringe with heparine;

- Turn off solutions according to medical prescriptions;

- Put on non-sterile gloves;

- Wash the system with physiological solution for returning blood in the arterial and venous routes;

- Wash hands;

- Put on mask;

- Put on gloves;

- Disconnect the extension of one of the catheter routes, inject physiological solution or distilled water and then inject $1.5 \mathrm{ml}$ of heparine, clamp the route and connect the sterile occlusion cover, repeat the sequence with the other route;

- Put on sterile glove and proceed with the dressing with antiseptic solution, gauzes and occlude with microporous adhesive tape.

In general, for each dialysis procedure, there is one installation and one turnoff. The number and type of baths and anticoagulants varies in the maintenance procedure, according to the medical prescription and the patient's clinical conditions. 
Computation of time and labor costs

It was determined by the Institution that the dialysis procedures should be performed by Nurses from the Units, after training and with constant supervision by the Dialysis Nurse.

For the estimation of time, the total hours spent on the realization of each procedure was considered because the nurse, besides his(er) direct intervention, supervises the patient during the dialysis and remains available in case problems occur.

For the estimation of salaries, data from the Institute's Human Resource Department were obtained, which provided: remuneration, total taxes and benefits of nurses from the ICU and Dialysis sectors. Next, the average of values and the average cost per hour were computed, which was $\mathrm{R} \$ 22.50$. Thus, to calculate the nurses' labor cost in each procedure, the hour cost of $\mathrm{R} \$ 22.50$ was multiplied by the total hours of each procedure.

Input cost calculation

In the analysis of each procedure registered on the patients' files, the quantities of material, medication and volumes of solutions used were computed and, next, this information was registered in a worksheet.

Unit cost data of the inputs were obtained by consulting the Material Administration System (MCS), an internal computer system. Some medications and solutions produced in the Institutions were consulted directly at the Pharmacy Division.

Three kinds of solutions can be used at the institution. Two are industrialized (peritoneal dialysis and lactate-based dialysis) and the other is prepared at the unit itself by the nurse who performs the procedure. Two kinds of solutions can be used for the anticoagulation: citrate and heparine solutions or, due to the patients' clinical condition, only washing the system with physiological solution more intensely, according to the medical prescription.

Some standards were set for the charge of some inputs, for example: the infusion pump is changed every 72 hours, according to institutional routine; a piece of $20 \mathrm{~cm}$ of wide microporous adhesive tape used was considered in the turnoff for computation, and others.

After finishing the cost calculation of each of the 93 procedures in the data collection instrument, amounts were transferred to an electronic worksheet for analysis with the study variables.

\section{RESULTS}

Socio-Demographic and Clinical Characterization of Patients

Men predominated (62\%) in the sample. The ARF diagnosis was described for $76 \%$ of the patients.

Regarding origin, $54 \%$ of the patients originated from nursing wards and $38 \%$ from the Emergency Room. The main motives for hospitalization at the ICU were: respiratory failure $(30 \%)$, decreased level of consciousness (18\%), post operative (16\%) and septic shock (12\%). In total, $86 \%$ died.

Table 1 - Distribution of the number of patients according to age, time of stay in days at the ICU and number of procedures per patient. São Paulo, 2006

\begin{tabular}{|c|c|c|c|c|c|}
\hline & $\mathbf{N}$ & Average & Standard Error & Minimum & Maximum \\
\hline$\overline{\text { Age }}$ & 50 & 60.8 & 17.3 & 21.0 & 87.0 \\
\hline Stay in days at ICU & 50 & 19.2 & 22.8 & 2.0 & 112.0 \\
\hline $\begin{array}{l}\text { Number of procedures } \\
\text { per patient }\end{array}$ & 50 & 1.9 & 1.2 & 1.0 & 6.0 \\
\hline
\end{tabular}

Table 1 shows that there was great variability in the sample regarding age, time of stay at the ICU and the quantity of procedures per patient.

Procedure Cost

Table 2 - Distribution of the number of procedures according to length in hours, labor, inputs and total costs. São Paulo, 2006

\begin{tabular}{|c|c|c|c|c|c|}
\hline & $\mathbf{N}$ & Average & Standard Error & Minimum & Maximum \\
\hline Length in hours & 93 & 26. & 15.1 & 1.0 & 80.0 \\
\hline Labor costs & 93 & 592.04 & 345.52 & 22.50 & 1800.00 \\
\hline Input costs & 93 & 1473.32 & 708.00 & 711.15 & 5194.18 \\
\hline Total Costs & 93 & 2065.36 & 929.97 & 733.65 & 6994.18 \\
\hline
\end{tabular}

It is observed in Table 2 that the average labor cost was $\mathrm{R} \$ 592.04$ and also presented great variability, because the length of the procedure directly influences the labor cost.

Therefore, it is concluded that the inputs cost (consumption material, medication and solutions) corresponded to almost three times the labor cost.

The total cost varied considerably, from $\mathrm{R} \$$ 733.65 to $R \$ 6,994.18$, with an average cost of $R \$$ $2,065.36$. The input cost represented $71.3 \%$ of the total cost and labor $28.7 \%$. 
Table 3 - Distribution of the number of procedures according to total costs of installation, turnoff, change of system and capillary dyalizer. São Paulo, 2006

\begin{tabular}{lccccc}
\hline & N & \multicolumn{3}{c}{ Average } & Standard Error \\
\hline Total cost - installation & 93 & 830.31 & 361.18 & 632.94 & 2531.76 \\
Total cost - tumoff & 93 & 7.56 & 3.29 & 5.76 & 23.04 \\
$\begin{array}{l}\text { Total cost - change of } \\
\text { system }\end{array}$ & 34 & 812.94 & 568.83 & 628.18 & 3769.08 \\
$\begin{array}{l}\text { Total cost - change of } \\
\text { capillary dyalizer }\end{array}$ & 40 & 70.74 & 32.30 & 51.45 & 154.35 \\
\hline
\end{tabular}

Table 3 presents the descriptive statistics of installation, turnoff, change of system and capillary dyalizer costs, considering only the procedures in which the system or capillary dialyzer were changed. Thus, the average cost was $\mathrm{R} \$ 812.94$ for procedures that included change of system. We verified that almost a third of the procedures needed change of system, while $43 \%$ of the procedures required change of capillary dyalizer.

Table 4 - Distribution of the number of procedures according to length and total cost of each solution. São Paulo, 2006

\begin{tabular}{lccccc}
\hline & \multicolumn{6}{c}{ N } & \multicolumn{4}{c}{ Average Standard Error Minimum Maximum } \\
\hline $\begin{array}{l}\text { Length in hours - } \\
\text { (prepared bath) }\end{array}$ & 66 & 23.15 & 15.31 & 1.00 & 80.00 \\
$\begin{array}{l}\text { Total cost - solution } \\
\text { (prepared bath) }\end{array}$ & 66 & 213.17 & 118.88 & 54.00 & 720.00 \\
$\begin{array}{l}\text { Length in hours - } \\
\text { peritoneal dialysis solution }\end{array}$ & 29 & 22.72 & 12.14 & 3.00 & 53.00 \\
$\begin{array}{l}\text { Total cost - peritoneal } \\
\text { dialysis solution }\end{array}$ & 29 & 167.23 & 85.90 & 34.35 & 386.90 \\
$\begin{array}{l}\text { Length in hours - lactate- } \\
\text { based dialysis solution }\end{array}$ & 11 & 25.73 & 13.09 & 9.00 & 57.00 \\
$\begin{array}{l}\text { Total cost - lactate-based } \\
\text { dialysis solution }\end{array}$ & 11 & 317.94 & 146.23 & 112.05 & 646.38 \\
\hline
\end{tabular}

Descriptive statistics of length and cost for each solution can be observed in Table 4, considering only procedures in which each solution was used. This way, for the procedures that used peritoneal dialysis solution, the average cost for this solution was $R \$$ 167.23, which is the lowest of all solutions.

Table 5 - Distribution of the number of procedures according to length in hours and total cost of each anticoagulant. São Paulo, 2006

\begin{tabular}{|c|c|c|c|c|c|}
\hline & $\mathbf{N}$ & Average & ndard E & Minimun & $\overline{\text { Maximum }}$ \\
\hline $\begin{array}{l}\text { Length in hours - Citrate } \\
\text { anticoagulant }\end{array}$ & 32 & 27.16 & 15.51 & 6.00 & 61.00 \\
\hline $\begin{array}{l}\text { Total cost - Citrate } \\
\text { anticoagulant }\end{array}$ & 32 & 131.41 & 43.73 & 80.10 & 224.01 \\
\hline $\begin{array}{l}\text { Length in hours - heparin } \\
\text { anticoagulant }\end{array}$ & 25 & 26.04 & 13.86 & 3.00 & 53.00 \\
\hline $\begin{array}{l}\text { Total cost - heparin } \\
\text { anticoagulant }\end{array}$ & 25 & 52.43 & 8.46 & 39.24 & 76.33 \\
\hline Length in hours - ps lavage & 42 & 22.62 & 14.91 & 1.00 & 80.00 \\
\hline Total cost - ps lavage & 42 & 16.58 & 16.00 & 1.90 & 87.30 \\
\hline
\end{tabular}

It is observed in Table 5 that, in the descriptive statistic of length and costs for each anticoagulant, only those procedures using the anticoagulant are considered. This way, the average cost for the procedures that used Citrate anticoagulant was $\mathrm{R} \$$ 131.41, which was the highest, but also represented the longest average time.

\section{DISCUSSION}

The study showed that the dialysis procedure is complex and involves many variables, which makes it difficult to estimate costs.

The main variables found in this study influencing procedure costs were: patients' clinical conditions; quantity of installations and turnoffs, changes in the system and capillary dyalizer.

The patients' clinical conditions mainly influence the length of the procedures, due to the flow of baths, and the alteration in the composition of dialysis solutions, which requires greater attention by the nursing team.

What is usually considered a dialysis session is its installation and turnoff. However, due to occurrences with patients or problems with equipment or material, the procedure can be interrupted in order to solve the problem, consequently leading to a new installation or change of part of the system, which increase costs and, more importantly, cause inconveniences and risks for the patient. These problems must also be evaluated by the medical and nursing team in order to avoid and diminish waste of material and human resources.

Considering the factors mentioned, a great variability of costs was found, which reinforces the need to study the stratification of costs and prices according to the variables found. Hospitals have charged the same amount for a procedure that ranged from 733.65 to $R \$ 6,994.18$.

In view of the research results, it would be convenient if institutions, government, health operators and patients assessed the charge of the procedure by the number of installations and turnoffs and the development of the dialysis per hour. The hour cost of hemodialysis would be computed by the type of solution and anticoagulant, adding a fee for nursing and medical work. 


\section{CONCLUSIONS}

The study results showed great variability of time and material used in the dialysis procedures. The total cost varied from $\mathrm{R} \$ 733.65$ to $\mathrm{R} \$$ $6,994.18$, with an average cost of $R \$ 2,065.36$, while the inputs corresponded to $71.3 \%$ of total cost and $28 \%$ of labor.

This study presented several limitations, such as: exclusion of complementary exam cost and cost of extra replacements of medications and/or solutions; the exclusion of medical team work; the exclusion of equipments' depreciation cost; lack of opportunity for a detailed comparison of costs between types of solutions and anticoagulants used. Additionally, because it is a study using documental sources, there was some difficulty with unclear or dubious notations on the patients' files. Thus, this exploratory descriptive research needs to be broadened and replicated with a view to further knowledge and information.

However, this study offered important indications for the management of resources and costs in health and in nursing.

\section{REFERENCES}

1. Homsi E. Insuficiência renal aguda em UTI. São Paulo: Atheneu; 1998

2. Lima EQ, Burdmann EA, Yu L. Adequação de diálise em insuficiência renal aguda. J Bras Nefrol. 2003;25(3):149-54. 3. Yu L, Abensur H, Barros EJG, Homsi E, Burdmann EA, Cendoroglo Neto $M$ et al. Insuficiência renal aguda: diretriz da Sociedade Brasileira de Nefrologia. J Bras Nefrol. $2002 ; 24(1): 37-9$.

4. Francisco IMF, Castilho V. A enfermagem e o gerenciamento de custos. Rev Esc Enferm USP. 2002; 36(3):240-4.

5. Bellomo R, Mehta R. Acute renal replacement in the intensive care unit: now and tomorrow. New Horiz. 1995; 3(4):760-7. 6. van Bommel EFH, Bouvy ND, So KL, Zietse R, Vincent $H H$, Bruining $\mathrm{HA}$, et al. Acute dialytic support for the critically ill: intermittent hemodialysis versus continuous arteriovenous hemodiafiltration. Am J Nephrol. 1995;15(3):192-200.

7. Gilbert RW, Caruso DM, Foster KN, Canulla MV, Nelson ML, Gilbert EA. Development of a continuous renal replacement program in critically ill patients. Am J Surg. 2002; 184(6):526-32.

8. Hamel MB, Philipps RS, Davis RB, Desbiens N, Connors AFJr, Teno JM et al. Outcomes and cost-effectiveness of initiating dialysis and continuing aggressive care in seriously ill hospitalized adults. SUPPORT Investigators. Study to Understand Prognoses and Preferences for Outcomes and Risks of Treatments. Ann Intern Med. 1997; 127(3):195-202.

9. Korkeila M, Ruokonen E, Takala J. Costs of care, long-term prognosis and quality of life in patients requiring renal replacement therapy during intensive care. Intensive Care Med. 2000; 26(12):1824-31.

10. Manns B, Doig CJ, Lee H, Dean S, Tonelli M, Johnson D et al. Cost of acute renal failure requiring dialysis in the intensive care unit: clinical and resource implications of renal recovery. Crit. Care Med. 2003; 31(2)449-55.

11. Vitale C, Bagnis C, Marangella M, Belloni G, Lupo M, Spina $G$ et al. Cost analysis of blood purification in intensive care units: continuous versus intermittent hemodiafiltration. J Neprhrol. 2003; 16(4):572-9. 